\title{
Oxygen uptake, heart rate, and work rate at ventilatory threshold for treadmill walking against a horizontal impeding force
}

\author{
Akihiro Azuma \\ Course of Liberal Arts, Fukui National College of Technology, Sabae, Japan; aazuma@fukui-nct.ac.jp
}

Received 28 October 2013; revised 27 November 2013; accepted 2 December 2013

Copyright (C) 2013 Akihiro Azuma. This is an open access article distributed under the Creative Commons Attribution License, which permits unrestricted use, distribution, and reproduction in any medium, provided the original work is properly cited.

\begin{abstract}
The purpose of this study was to compare the ventilatory threshold (VT) between treadmill walking against a horizontal impeding force (horizontal load walking) and a cycle ergometer exercise. Seven adult men volunteered to participate in this study. They performed horizontal load walking (velocity: $1.11 \mathrm{~m} / \mathrm{s}$ ) and a cycle ergometer exercise (pedaling frequency: $60 \mathrm{rpm}$ ), with loads imposed using a ramp slope technique. Oxygen uptake at the VT during horizontal load walking was greater than that during a cycle ergometer exercise $(p<0.05)$, whereas the opposite was noted for the work rate at VT $(p<$ $0.05)$. The greater metabolic cost was because of the small output (work rate at VT) incurred during horizontal load walking. This suggested that the muscle mass recruited for exercise would be much greater for horizontal load walking than a cycle ergometer exercise because pedaling requires fewer muscles (lower extremities). In addition, a high reliability of VT during horizontal load walking was indicated from the correlation coefficient, standard error, and the confidence coefficient in two trials for the same subjects, which were $0.97,0.097 \mathrm{~L} / \mathrm{min}$, and 0.96 , respectively. These results suggest that horizontal load walking may be a modality for aerobic conditioning.
\end{abstract}

Keywords: Vetilatory Threshold; Horizontal Load; Ramp Slope; Walking; Cycling

\section{INTRODUCTION}

Level walking and cycle ergometer exercise are representatives of different modes of exercise for health and fitness. For a cycle ergometer exercise, the load determines the exercise intensity at a certain pedal frequency. In contrast, the intensity of level walking depends on velocity. In other words, the velocity, which is a factor of the "force-velocity relationship" during muscular contraction, controls the exercise intensity of level walking. However, during treadmill walking against a horizontal impeding force (horizontal load walking) at a constant velocity, an increase of load is considered as the increase of force in the force-velocity relationship.

Experimental studies of locomotion using a horizontal load on a treadmill began in order to determine the mechanical efficiency of movement. Lloyd and Zacks [1] estimated the mechanical efficiency (Apparent Efficien$\mathrm{cy}, \mathrm{AE}$ ) during treadmill running on the basis of the rate of increasing energy expenditure for increment of work rate (load $\times$ velocity). Asmussen and Bonde-Petersen [2] also reported about the $\mathrm{AE}$ of walking and running using a similar technique according to Lloyd and Zacks [1]. Bijker et al. [3] compared the delta efficiency of running with that of a bicycle ergometer exercise. Furthermore, the $\mathrm{AE}$ of running was compared between adults and children [4], and the effect of footwear (Japanese wooden clogs) on the $\mathrm{AE}$ of walking was also evaluated [5]. In those studies, the horizontal load was gradually increased during consecutive exercise bouts (constant time interval), and the corresponding metabolic cost was determined. Recently, a ramp slope technique has been widely used with cycle ergometer tests as a means to incrementally increase the load. However, a horizontal load on a treadmill using this technique has not been developed.

In general, a ramp slope exercise test is a technique for imposing consecutive, sequential linear loads using an electrically-braked cycle ergometer, which is controlled by a computer. With this technique, subjects continue to exercise up to their maximal or sub-maximal levels, and 
medical and physiological parameters such as exercise electrocardiography readings, maximum oxygen uptake, and the ventilatory threshold (VT) can be determined. In particular, the VT is recognized as the level to safely improve cardio-respiratory function and endurance by physiologists and physical trainers, and is also known to minimize the discomfort associated with lactate accumulation during exercise [6]. Because it was clear that the energy cost increased linearly with the linear increment of a horizontal load in previous studies on efficiency, the VT during horizontal load walking may be detectable using a ramp slope technique.

Level walking is one of the moderate aerobic exercises that can easily be done by anyone. In addition, horizontal load walking does not require fast or quick movements even if the exercise intensity is increased because the walking velocity is constant. Therefore, it would be expected that aerobic conditioning at the VT level during horizontal load walking would be safe and useful for an exercise prescription. In contrast, several studies have found that the VT differed between different modes of exercise $[7,8]$. Therefore, it was assumed that the VT of horizontal load walking could be characterized by comparing it with that of a cycle ergometer exercise.

The purposes of this study were to determine the VT of horizontal load walking and to compare the VT of horizontal load walking with that of a cycle ergometer exercise.

\section{METHODS}

\subsection{Subjects}

Subjects were seven healthy male adults who had no history of orthopedic diseases that could affect walking and cycling (mean \pm SD; age: $30.9 \pm 7.0$ years; height: $170.4 \pm 8.8 \mathrm{~cm}$; body weight: $66.1 \pm 14.1 \mathrm{~kg}$ ). The purpose, procedures, and risks of the experiment were explained before participating in this study, and written informed consent was obtained from all subjects. This study followed the principles outlined in the declaration of Helsinki.

\subsection{Procedures}

On the basis of methods described in the previous studies, subjects performed horizontal load walking at $1.11 \mathrm{~m} / \mathrm{s}(4 \mathrm{~km} / \mathrm{h})$ [2,5]. Horizontal loads were imposed using weights in a small basket that was connected to a wire, which was passed through a pulley and attached to a band around a subject's waist (Figure 1). A ramp slope technique was used to load a sand bag weighing $0.16 \mathrm{~kg}$ in the basket every 6 seconds. The rate (slope) of the increment was $16.7 \mathrm{~W} / \mathrm{min}$. Subjects walked without loads for $3 \mathrm{~min}$ and the horizontal load by the ramp slope began to be imposed after unloaded walking. Loaded

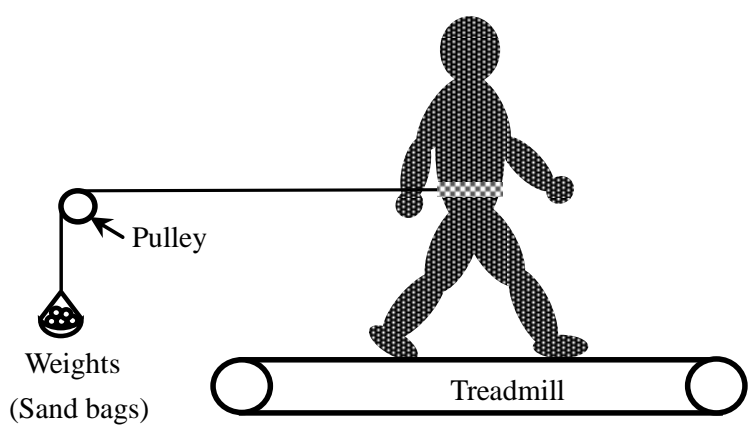

Figure 1. Schematic diagram of the experimental set-up.

walking was continued until subjects achieved up to $85 \%$ of their estimated maximum heart rates (HRmax, estimated by using the formula 220 -age). The slope was preliminarily decided so as to reach $85 \%$ of HRmax during load walking for almost $10 \mathrm{~min}$. Subjects also performed a cycle ergometer exercise at $60 \mathrm{rpm}$, and a ramp slope was imposed by an electrically-braked cycle ergometer (Combi, 75XLIIME, Japan). The slope was set at $20 \mathrm{~W} /$ min by an automated program incorporated in the ergometer after $3 \mathrm{~min}$ of unloaded pedaling. Subjects also continued to perform pedaling up to $85 \%$ of their HRmax like a case of the horizontal load walking.

\subsection{Measurement of Ventilatory Threshold}

Expired gas during exercise was continuously collected by the breath-by-breath method. Ventilation $\left(\dot{\mathrm{V}}_{\mathrm{E}}\right)$, oxygen uptake $\left(\dot{\mathrm{V}}_{2}\right)$, carbon dioxide production $\left(\dot{\mathrm{V} C O}{ }_{2}\right)$, end-tidal pressure of $\mathrm{O}_{2}\left(\mathrm{P}_{\mathrm{ET}} \mathrm{O}_{2}\right)$, and end-tidal pressure of $\mathrm{CO}_{2}\left(\mathrm{P}_{\mathrm{ET}} \mathrm{CO}_{2}\right)$ were measured using a respiration gas analyzer (Minato Medical Science, AE300SRC, Japan). Heart rate was monitored at the same time with a telemetry system (Nihon Kohden, LIFESCOPE6, Japan). VT was determined as the beginning of the nonlinear increase in $\dot{\mathrm{V}}_{\mathrm{E}}$ and $\dot{\mathrm{V}} \mathrm{CO}_{2}$ and an increase of $\dot{\mathrm{V}}_{\mathrm{E}} / \dot{\mathrm{VO}}_{2}$ without an increase in $\dot{\mathrm{V}}_{\mathrm{E}} / \dot{\mathrm{V}}_{\mathrm{CO}}$, while $\mathrm{P}_{\mathrm{ET}} \mathrm{O}_{2}$ began to increase systematically without a decrease in $\mathrm{P}_{\mathrm{ET}} \mathrm{CO}_{2}$ [9-11]. Oxygen uptake ( $\dot{\mathrm{VO}}_{2} @ \mathrm{VT}$, $\mathrm{L} / \mathrm{min}$ and $\mathrm{mL} / \mathrm{kg} \cdot \mathrm{min}$ ), heart rate (HR@VT, beats/min), and work rate (WR@VT, W) at VT were compared between horizontal load walking and the cycle ergometer exercise. The VT during horizontal load walking was measured twice and the measured variables during each trial were averaged for comparisons.

\subsection{Statistical Analysis}

Paired t-tests were used to compare the results for each VT variable ( $\mathrm{VO}_{2} @ V T$, HR@VT, and WR@VT) between horizontal load walking and cycle ergometer exercise. Pearson's correlation coefficient, the standard error of estimation, and a confidence coefficient were also determined for two trials of $\dot{\mathrm{VO}}_{2} @ \mathrm{VT}$ during horizon- 
tal load waking. The confidence coefficient was based on the results of one-way analysis of variance [11]. A pvalue of $<0.05$ was considered significant.

\section{RESULTS}

The VT during horizontal load walking could be determined for all our study subjects using the ramp slope technique, as shown in Figure 2. Table 1 shows a com-

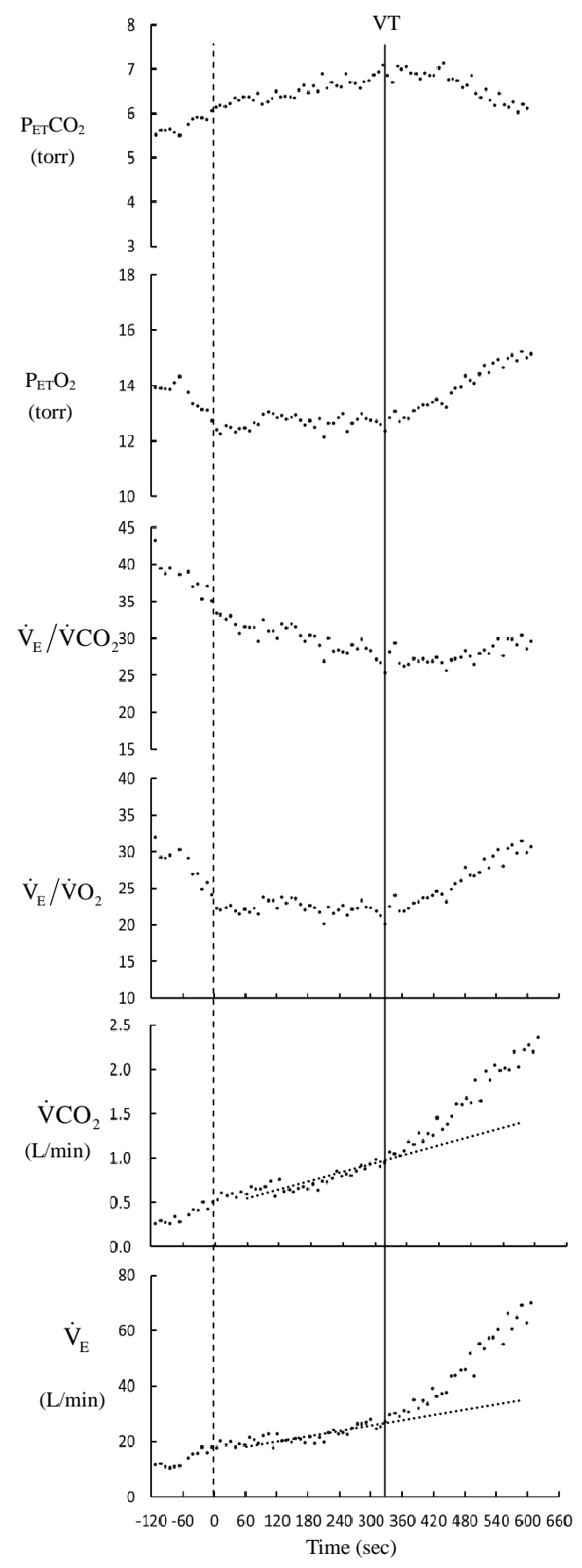

Figure 2. A typical subject's response to a ramp exercise test during horizontal load walking.
Table 1. Comparisons of oxygen uptake, heart rate, and work rate at ventilatory threshold (VT) between horizontal load walking and cycle ergometer exercise.

\begin{tabular}{cccccccc}
\hline Variable & \multicolumn{3}{c}{$\begin{array}{c}\text { Horizontal load } \\
\text { walking }\end{array}$} & \multicolumn{4}{c}{$\begin{array}{c}\text { Cycle ergometer } \\
\text { exercise }\end{array}$} \\
\hline$\dot{\mathrm{VO}} \mathrm{O}_{2} @ \mathrm{VT}(\mathrm{L} / \mathrm{min})$ & $1.705^{*}$ & \pm & 0.350 & 1.431 & \pm & 0.287 \\
$\dot{\mathrm{VO}} \mathrm{O}_{2} @ \mathrm{VT}(\mathrm{mL} / \mathrm{kg} \cdot \mathrm{min})$ & $26.06^{*}$ & \pm & 3.88 & 21.94 & \pm & 4.07 \\
$\mathrm{HR} @ V T($ beats/min) & 127.7 & \pm & 6.6 & 120.1 & \pm & 8.5 \\
WR@VT (W) & $95.2^{*}$ & \pm & 25.2 & 123.7 & \pm & 21.0 \\
\hline Values are Means $\pm \mathrm{SDs}(\mathrm{n}=7) .{ }^{*} p<0.05$. & & & &
\end{tabular}

parison of the VT results between horizontal load walking and cycle ergometer exercise. $\dot{\mathrm{V}}_{2} @ \mathrm{VT}$ during horizontal load walking was significantly greater than that during the cycle ergometer exercise $(p<0.05)$, whereas the opposite was found for WR@VT $(p<0.05)$. In addition, HR@VT during horizontal load walking was slightly higher than that during the cycle ergometer exercise, although this difference was not significant. According to comparison among two trials for each subject, the correlation coefficient, standard error, and the confidence coefficient were $0.97,0.097 \mathrm{~L} / \mathrm{min}$, and 0.96 , respectively.

\section{DISCUSSION}

Greater $\dot{\mathrm{VO}}_{2} @ \mathrm{VT}$ during horizontal load walking was observed as compared with that during a cycle ergometer exercise. This suggests that muscle mass recruited for exercise is much greater during horizontal load walking than during a cycle ergometer exercise because pedaling requires fewer muscles (lower extremities). It is well known that the maximal oxygen uptake depends on the muscle mass recruited for exercise [12-15]. Similarly, some reports showed that $\dot{\mathrm{VO}}_{2} @ \mathrm{VT}$ during rowing or running was greater than that during a cycle ergometer exercise $[7,8]$. It is plausible that whole body exercises as compared with partial exercises yield higher values for aerobic parameters. Furthermore, it was postulated that the greater metabolic cost was caused by the small output (WR@VT) during horizontal load walking.

The reliability of the VT during a cycle ergometer exercise has been questioned in previous studies. Davis et al. [16] reported that the correlation coefficient was 0.91 and the standard error of estimation was 0.085 - $0.131 \mathrm{~L} /$ min for $\dot{\mathrm{V}}_{2} @ \mathrm{VT}$ according to two trials for the same subjects $(\mathrm{n}=9)$. Caiozzo et al. [11] also reported on the reliability of $\dot{\mathrm{VO}}_{2} @ \mathrm{VT}$ according to two trails $(\mathrm{n}=20)$, which accounted for approximately 0.8 of the confidence coefficient. The results for the correlation coefficient, standard error, and confidence coefficient were comparable to those in previous studies (cycle ergometer exercises). This indicates that the VT during horizontal load 
walking is a reliable, practical index for aerobic conditioning.

\section{CONCLUSION}

The results of this study showed that horizontal load walking can be useful from the perspective of expending a greater metabolic cost than with a cycle ergometer exercise at the VT level. This physiological benefit suggests that horizontal load walking could be prescribed as an effective aerobic exercise.

\section{REFERENCES}

[1] Lloyd, B.B. and Zacks, R.M. (1972) The mechanical efficiency of treadmill running against a horizontal impeding force. Journal of Physiology, 223, 355-363.

[2] Asmussen, E. and Bonde-Petersen, F. (1974) Apparent efficiency and storage of elastic energy in human muscles during exercise. Acta Physiologica Scandinavica, 92, 537-545.

http://dx.doi.org/10.1111/j.1748-1716.1974.tb05776.x

[3] Bijker, K.E., De Groot, G. and Hollander, A.P. (2001) Delta efficiencies of running and cycling. Medicine and Science in Sports and Exercise, 33, 1546-1551. http://dx.doi.org/10.1097/00005768-200109000-00019

[4] Cooke, C.B., McDonagh, M.J., Nevill, A.M. and Davies, C.T. (1991) Effects of loadon oxygen intake in trained boys and men during treadmill running. Journal of Applied Physiology, 71, 1237-1244.

[5] Azuma, A. and Yamamoto, H. (2001) Energy cost and mechanical efficiency of walking with the Japanese style wooden clogs. Japanese Journal of Biomechanics in Sports and Exercise, 5, 144-148.

[6] Swaine, I.L., Emmett, J., Murty, D., Dickinson, C. and Dudfield, M. (1995) Rating of perceived exertion and heart rate relative to ventilatory threshold in women. British Journal of Sports Medicine, 29, 57-60. http://dx.doi.org/10.1136/bjsm.29.1.57

[7] Bunc, V. and Leso, J. (1993) Ventilatory threshold and work efficiency during exercise on a cycle and rowing ergometer. Journal of Sports Sciences, 11, 43-48. http://dx.doi.org/10.1080/02640419308729962

[8] Hoffmann, J.J., Loy, S.F., Shapiro, B.I., Holland, G.J., Vincent, W.J., Shaw, S. and Thompson, D.L. (1993) Specificity effects of run versus cycle training on ventilatory threshold. European Journal of Applied Physiology, 67, 43-47. http://dx.doi.org/10.1007/BF00377703

[9] Nemoto, I. and Miyashita, M. (1980) Aerobic and anaerobic threshold of Japanese male adults. Journal of Human Ergology, 9, 183-189.

[10] Davis, J.A., Whipp, B.J., Lamarra, N., Huntsman, D.J., Frank, M.H., Wasserman, K. (1982) Effect of ramp slope on determination of aerobic parameters from the ramp exercise test. Medicine and Science in Sports and Exercise, 14, 339-343.

[11] Caiozzo, V.J., Davis, J.A., Ellis, J.F., Azus, J.L., Vandagriff, R., Prietto, C.A. and McMaster, W.C. (1982) A comparison of gas exchange indices used detect the anaerobic threshold. Journal of Applied Physiology, 53, 1184-1189.

[12] Åstrand, P.-O. and Saltin, B. (1961) Maximal oxygen uptake and heart rate in various types of muscular activity. Journal of Applied Physiology, 16, 977-981.

[13] Stenberg, J., Åstrand, P.-O. and Ekblom, B. (1967) Hemodynamic response to work with different muscle groups, sitting and supine. Journal of Applied Physiology, 22, 61-70.

[14] Reybrouk, T., Heigenhauser, G.H. and Faulkner, J.A. (1975) Limitations to maximum oxygen uptake in arm, leg, and combined try. Journal of Applied Physiology, 38, 774-779.

[15] Bergh, U., Kanstrup, I.L. and Ekblom, B. (1976) Maximal oxygen uptake during exercise with various combinations of leg and arm work. Journal of Applied Physiology, 41, 191-196.

[16] Davis, J.A., Frank, M.H., Whipp, B.J. and Wasserman, K. (1979) Anaerobic threshold alterations caused by endurance training in middle-aged men. Journal of Applied Physiology, 46, 1039-1046. 